\title{
Towards a Framework of Co-Design Sessions with Children
}

\author{
Emanuela Mazzone ${ }^{1}$, Janet C. Read ${ }^{1}$, and Russell Beale ${ }^{2}$ \\ ${ }^{1}$ Child Computer Interaction Group, University of Central Lancashire, \\ Preston PR1 2HE, UK \\ \{EMazzone, JCRead\}@uclan.ac.uk \\ ${ }^{2}$ Advanced Interaction Group, School of Computer Science, University of Birmingham, \\ Birmingham, UK, B15 2TT \\ R.Beale@cs.bham.ac.uk
}

\begin{abstract}
In this poster we present a framework of the elements of co-design sessions with children. The involvement of children in the design process is important in order to understand their needs but it is often considered a complex practice. Considering a thorough appreciation of this practice as the basis for its accurate application, we addressed its complexity in a framework. To do so, we identified and organised elements that have an impact on co-design sessions in who, where, when, what and how dimensions. This theoretical framework aims to support novice practitioners in their decisions when coordinating co-design sessions.
\end{abstract}

Keywords: Interaction Design, Children, Co-Design, Framework.

\section{Introduction}

A User-Centred approach is recommended in the design of novel technology for children in order to reduce the discrepancy between the system conceptual model, defined by adult designers, and the mental model of children users. Designers usually refer to cognitive development stages of children to identify the users' capabilities and skills that need to be mirrored in the product requirements, i.e. [1, 2]. In addition to the reference to developmental models, it has become a common practice to involve children during the design and evaluation of products to make sure that the requirements are actually met. Engaging children throughout the design process can take several forms depending on the degree of participation children are allowed, from simply users to equal partners [3]. Over the last decade, there has been an increasing tendency to explore children's involvement in the early stages of the design process, i.e $[5,6,4,7]$. The broad term 'co-design' means that users are asked to do things, instead of only being asked about a topic or observed in specific situations; this takes the designers to a deeper level of understanding of the user's way of thinking about the world [8]. When it comes to children, engaging them in design activities also helps overcome the limitations that arise from their not fully developed language and social skills, while at the same time encouraging their potential for creativity and imagination. 
As concluded by Nesset and Large [9], when reviewing design projects that involved children, the advantages in terms of innovation and appropriateness of design outweigh negative factors, like cost in terms of time and resources needed. Therefore, "the real issue would seem to be [...] how to more effectively engage children in the design process" [10]. In a similar way, in a special issue of the coDesign journal, all the studies agreed on the value of including children in the early stages of design and in the decision making process, but highlighted practical difficulties and the need for guides and directions for designers and researchers who want to organise and conduct meaningful participations [11]. More recently, [12] proposed a framework for supporting the choice of certain methods by relating the characteristics of children with the characteristics of design methods. As suggested by [13], research that aims to support the Interaction Design practice has to be based on a deep understanding of design as a complex human activity of inquiry and action. Taking all these research directions into account, we wanted to increase the awareness of all the elements involved in a co-design session that influence its output by organising them into a framework. The framework we present in this poster is of 'explanatory' [14] as it presents concepts or dimensions to consider in designing experiences, rather than presenting a set of steps or principles to follow.

\section{Defining a Framework}

From the analysis of the research reported in the literature and from our own experience in the field [15-17] we identified elements that are determinant in codesign sessions with children and need to be considered when managing resources for gaining access to children, for running the co-design sessions or for analysing the results. We consider these elements to also play a significant role in what we identified as critical aspects for the researchers, i.e.: determining researchers' expectations of the outputs, considering children's perspectives, pondering practical constraints, dealing with not-programmed incidents, and managing sessions' outputs. Our aim is to organise the complexity of co-design with children in a way that highlights the importance of each element in the handling of a co-design session. We understand the coordination of a design session as defining the design objectives and variables to involve in the session. Once researchers identify the objectives and the available resources as initial requirements, the decisions concern all those elements involved in the experience of the session. We adopted a who-what-when-where-how (WH/HW) structure as an easy-to-remember way to group these factors, also used by [18] for planning evaluation sessions. The $5 \mathrm{WH} / \mathrm{HW}$ dimensions are presented as tables to summarise the implications behind the decisions on the single variables involved in the sessions ${ }^{1}$.

The who section includes consulting experts to support and validate the definition of activities. These experts can be teachers or developmental and educational experts whose advice is strategic for understanding children's skills and potential contribution. In the same section facilitators, like observers or assistants, are

1 See http://193.61.245.74/interact-poster.pdf for a version of the framework described here. 
considered - these need to share the same approach on the activities, understand their role, comprehend the activity goal, and the expected output. In this respect researchers should be aware of observers' effect and countercheck possible influences this may have on children's contributions. 'Children' do not appear as a specific variable of this section: since, as they are the main focus of the design session, their perspectives are addressed in other variables (i.e. experts advice, grouping, fun, distractions, etc.). For example, grouping strategies have an effect on the session's output: working in group can provoke discussion and chaining of ideas but may inhibit more introvert children, while individual work has the side effect of taking more time or leading to less ideas $[12,16]$.

The where section presents hints for space location, either familiar contexts for children but less controllable for researchers, or lab-type spaces that are less natural contexts for children. Concerning space distribution, children doing activities simultaneously in the same room can save time and resources but there will be an increase of chaos and distractions.

For the when section, options are presented for time management in terms of duration of activities and tasks, inclusion of breaks, and flexibility to adapt to unexpected events.

The what section includes a table with an alphabetic list of the most common techniques used in co-design sessions for children. Each technique has a brief description of its intended aim, some examples of possible variations, identification of the design stage of application, indication of the required children's skills, and a summary of the pros and cons of its employment. The introduction of props and of variants of creative techniques is important to trigger children's ideas and adapt to children's different ways of expressing themselves.

The how section considers ethics on privacy and security issues, together with tips on the different ways to brief the activity and hints on data collection. This last point is directly related to the analysis of outputs, which is essential to determine the session's success. For example, recording the progress of children's ideas and their explanations of the outputs can facilitate researchers' afterwards interpretation.

The aim of this framework is to support novice practitioners in reflecting on the implications of each element when taking decisions and outlining a detailed plan of their session. For example, if researchers want to involve children in the design of a computer game on a specific topic, they would check with the teacher whether that topic is suitable for the selected group of children to work on, or alternatively, look for a different group of children or adjust the topic to the available group. In a different example, if researchers are looking for a wide range of inputs in a limited time, they can ponder to organise a session with a whole group of children and recruit several assistant researchers to record the outputs rather than having small groups of children at a time to explore a topic in depth.

\section{Conclusions and Future Work}

The nature of the co-design with children practice and the endless variety of design situations and approaches makes it neither feasible nor sensible to create an exhaustive checklist for supporting novice practitioners in co-design sessions with children. In line with [13] and [19] views on research on design practice, design 
practitioners need concepts to 'think about' rather than 'guidelines' to tick off in a prescriptive way. In this paper we have organised elements involved in co-design sessions with children according to a WH/HW structure and presented their implications for the co-design session. This framework is the result of research based on literature and direct experience in the field and it provides theoretical references to use in practice. Once it is available to other practitioners of our research group, we will gather qualitative data to evaluate its effectiveness and refine its structure. Future work may also involve the creation of a practical tool based on this framework.

\section{References}

1. Antle, A.N.: The CTI framework. In: Proc. of TEI 2007, pp. 195-202. ACM, Louisiana (2007)

2. Gelderblom, H.: Designing software for young children. In: Proc. of IDC 2004, Maryland, pp. 121-122 (2004)

3. Druin, A.: The role of children in the design of new technology. BIT 21, 1-25 (2002)

4. Williamson, B.: The participation of children in the design of new technology. FutureLab (2003)

5. Bruckman, A., Bandlow, A.: Human-computer interaction for kids. In: The Humancomputer Interaction Handbook, pp. 428-440. L. Erlbaum Associates Inc., Mahwah (2003)

6. Jones, C., McIver, L., Gibson, L., Gregor, P.: Experiences obtained from designing with children. In: Proc. of IDC 2003, pp. 69-74. ACM, Preston (2003)

7. Sluis-Thiescheffer, W., Bekker, T., Eggen, B.: Comparing early design methods for children. In: Proceedings of IDC 2007, pp. 17-24. ACM, Aalborg (2007)

8. Sanders, E.: Postdesign and Participatory Culture. Presented at the Useful and Critical: The Position of Research in Design, Finland (1999)

9. Nesset, V., Large, A.: Children in the information technology design process: A review of theories and their applications. L. \& IS Research 26, 140-161 (2004)

10. Scaife, M., Rogers, Y., Aldrich, F., Davies, M.: Designing for or designing with? Informant design for interactive learning environments. In: Proceedings of CHI 1997, pp. 343-350. ACM, Atlanta (1997)

11. Woodcock, A.: Editorial. CoDesign 4, 193 (2008)

12. Sluis-Thiescheffer, R., Bekker, M., Eggen, J., Vermeeren, A., de Ridder, H.: Development and application of a framework for comparing early design methods for young children. Interacting with Computers 23, 70-84 (2011)

13. Stolterman, E.: The Nature of Design Practice and Implications for Interaction Design Research. International Journal of Design 2, 55-65 (2008)

14. Rogers, Y., Muller, H.: A framework for designing sensor-based interactions to promote exploration and reflection in play. IJ. of Human-Computer Studies 64, 1-14 (2006)

15. Kelly, S.R., Mazzone, E., Horton, M., Read, J.C.: Bluebells: a design method for child-centred product development. In: Proc. of NordiCHI 2006, pp. 361-368. ACM, Norway (2006)

16. Mazzone, E., Read, J., Beale, R.: Understanding children's contributions during informant design. In: Proc. of British HCI 2008, pp. 61-64. BCS, Liverpool (2008)

17. Mazzone, E., Tikkanen, R., Read, J.C., Iivari, N., Beale, R.: Integrating Children's Contributions in the Interaction Design Process. IJART (2012)

18. Markopoulos, P., Read, J., MacFarlane, S., Hoysniemi, J.: Evaluating Children's Interactive Products. Morgan Kaufmann, San Francisco (2008)

19. Schön, D.: The Reflective Practioner. Perseus (1983) 